\title{
A Pattern Generation Model Based on Neural Network ${ }^{\dagger}$
}

\section{Yutaka HATA*1 Makoto ISHIKAWA*2 Naotake KAMIURA*1 Riichi NAGURA*1 Kazuharu YAMATO*3}

\section{Introduction}

Nowadays, multi-layer perception with back propagation rule[1][2] has been used as a strong learning model network. Since the technique is developed based on human neuron action, it might be have an ability to demonstrate various human actions. Fuzzy logic technique[3] is a powerful framework that provides a way to represent and manipulate imprecise and uncertain information of human actions. There are some discussions[4]-[9] about the relations between fuzzy/neural computing and human cognition.

In this paper, we investigate a technique for modeling pattern generation using soft computing techniques[1]-[12]. Humans have the ability to generalize given instances of patterns. One might argue that the patterns are not actually stored verbatim, but rather compiled into an internal model. The subject of much research has been on using these models for recognition. The goal of our work is to investigate employing these models for pattern generation. In particular, from an internal model we would like to synthesize new patterns that share the characteristics of learned pattern. By observing the patterns generated by our model, we might be able to conclude something about its ability to create new patterns.

We first apply our model to binary function mapping and then demonstrate it on decision making and image generation applications. We show how input/output representations affect the learning and performance of our models. Our results show that our model can generate various patterns which are closely related to the given image and the

† ニューラルネットワークを䏘なパターン笔隹モデル

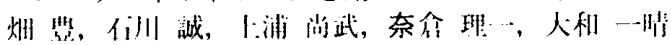

*1 Department of Computer Engineering. Himeji Institute of Technology

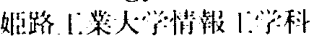

*2 Ishikawa Hospital 们川狱院

*3 Department of Information and Systems Engineering, Fukuoka Institute of Technology

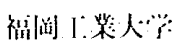

variety of generated images can be tractable by setting adequate parametors.

\section{Pattern Generation Model}

In this section, we define the binary functions and membership functions used in this paper. Let the set of binary logic values be $B=\{0,1\}$, any $n$-variable binary function is a mapping $B^{n} \rightarrow B$. The symbol $U$ denotes a universe of a mathematical construct. If $A$ is a finite subset of $U$ whose elements are $\mu_{1}$, $\mu_{2} \ldots \mu_{n}, A$ is expressed as $A=\mathrm{u}_{1}+\mathrm{u}_{2}+\ldots+\mathrm{u}_{n}$. A finite fuzzy subset of $U$ is expressed as

$$
\mathrm{F}=\mu_{1} / \mathrm{u}_{1}+\mu_{2} / \mathrm{u}_{2}+\ldots+\mu_{n} / \mathrm{u}_{n}
$$

where the $\mu_{i}, i=1,2, \ldots, n$, represent grades of membership of $\mu_{i}$, where $\mu_{i} \in[0,1]$.

Feed-forward adaptive networks considered in this paper will be defined as directed graphs with linear threshold nodes and edges labeled with real valued weights. A fully connected feed-forward neural network with an unlimited number of hidden units can compute any Boolean function. Such a general network model, therefore, will not constrain the solution space. The number of hidden layers is not unlimited but a minimal value is desirable. Rumelhart et. al. [1] clarified the number of hidden layers for some well-known learning problems, such as parity functions and symmetric patterns. In this paper, we use a neural network to model pattern generation. The core algorithm is as follows.

1. train a network on a problem

2. prune the structure

3 . add units with random connections

4. test new network against initial problem

5. update statistics of the connections in added units and how well new network solves old problem.

In detail, for a given feed-forward three-layered neural network with an unlimited number of hidden layers,

Step $0:$ set all connection weights and thresholds to small random values. 
Step 1: present teaching data to the neural network and adjust all connection weights and thresholds using back propagation.

Step $2:$ in every unit in the hidden layers calculate sum of errors, i.e., (teaching data-(output of the network)) ${ }^{2}$ for every input data when removing the unit. Prune the unit with the smallest sum of the errors on hidden layer in the neural networks.

Step 3: repeat step 2 until we obtain nonconverged network. For the last converged network, derive $W_{p}$ and $T_{p}$ to be the maximum value of connection weights and thresholds, respectively.

Step $4:$ add a hidden layer units and connect them to the last converged network obtained in Step 2.

Step 5 : set the newly added weights, $W_{\text {add }}$, and thresholds, $\mathrm{t}_{\text {add }}$, to small random values where $\left|W_{\text {add }}\right| \leq \beta\left|W_{p}\right|$ and $\left|t_{\text {add }}\right| \leq$ $\beta\left|\mathrm{T}_{p}\right|$ and then observe the output of the network for the original teaching data input. We define this as the Imagination Step in that a new network is formed as an extension of core concept network.

Step 6 : record how well new network solves the initial problem, where we consider the sets of outputs as the record, and go back to Step 5 some prespecified number of times.

Figure 1 illustrates one possible relationship between our model and human thinking.

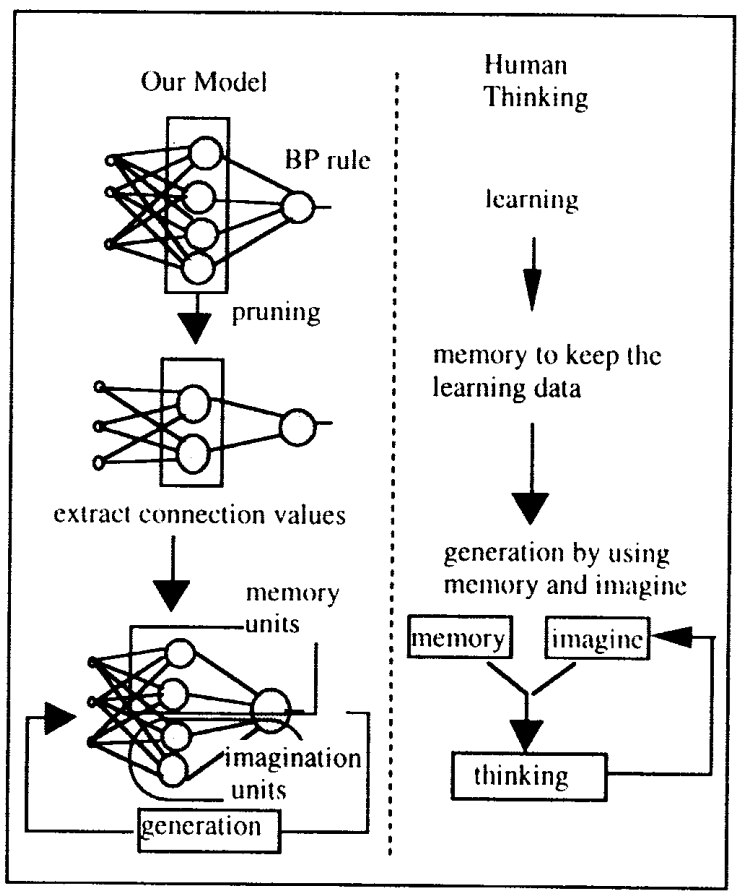

Figure 1 Our model and human thinking.

\section{A Model that Recognizes All Possible Patterns}

This section describes how our model exhibits human performance. If a human forgets a concept or a scheme, he/she might be able to reconstruct it from its label. For example, if we are asked to give an example of a monotone-increasing function, $F_{1}$, (but can't immediately recall one), we can try to narrow the set of possible functions by recalling the definition of the term of "monotone-increasing." We will use this problem as a first attempt to demonstrate this human performance using our network model. Without loss of generality and for the sake of simplicity, we first consider a twovariable case of generating monotone-increasing function.

Problem 1 : Generate all monotone-increasing functions.

Fuzzy Training Data Solution : We assign membership grades of 0.0 for $(0,0)$ and 0.5 for $(0,1)$ and $(1,0)$ and 1.0 for $(1,1)$ by the concept of "monotone increasing". Then, teaching data for $F_{1}$ can be expressed by :

$$
\begin{aligned}
F_{1}= & 0.0 /(0,0)+0.5 /(0,1)+0.5 /(1,0) \\
& +1.0 /(1,1)
\end{aligned}
$$

According to $F_{1}$, our teaching data are defined as four input/output pairs: $\mathrm{f}(0,0)=0, \mathrm{f}(0,1)=0.5$, $f(1,0)=0.5$ and $f(1,1)=1$ on our network learning algorithm. We obtained a three-layered neural network with one unit in the hidden layer. From this network, we constructed a two unit hidden layered network and repeated imagination step (step 4) 1,000 times $(\alpha=1.0, \beta=1.5)$. Table 1 tabulates all two-variable monotone-increasing functions, denoted by $\mathrm{f} 1, \ldots, \mathrm{f} 6$ for input $(\mathrm{x} 1$, $\mathrm{x} 2$ ). Table 2 shows the results obtained from our experiment. In it, $T h$ indicates the threshold value which determines whether the output is ' 0 ' or ' 1 ', "fi $(i=1 \ldots 6)$ " shows the function shown in Table 1 , and the final column shows the number of generated fi. In the column of "Error pattern," the table shows the function outputs not satisfying the monotoneincreasing specification. For example, "1011:6" means that function satisfying $f(0,0)=1, f(0,1)=$ $0, f(1,0)=1$ and $\mathrm{f}(1,1)=1$ appeared 6 times. "Sum \#" and "Error \#" shows the total number of successfully generated functions and their error functions, respectively. Considering Table 2 , we 
Table 1 All monotone-increasing functions.

\begin{tabular}{|c|c|c|c|c|c|c|}
\hline $\mathrm{x} 1 \times 2$ & $\mathrm{f} 1$ & $\mathrm{f} 2$ & $\mathrm{f} 3$ & $\mathrm{f} 4$ & $\mathrm{f} 5$ & $\mathrm{f} 6$ \\
\hline 00 & 0 & 0 & 0 & 0 & 0 & 1 \\
\hline 01 & 0 & 0 & 0 & 1 & 1 & 1 \\
\hline 10 & 0 & 0 & 1 & 0 & 1 & 1 \\
\hline 11 & 0 & 1 & 1 & 1 & 1 & 1 \\
\hline
\end{tabular}

succeeded in generating all monotone-increasing functions by giving our teaching data whatever $T h$ value took. We obtained the best result of generate all monotone-increasing functions without any loss using $\mathrm{Th}=0.5$.

Binary Training Data: We consider two two-input monotone-increasing functions :

$$
\begin{aligned}
& \mathrm{B}_{2}(=\mathrm{f} 5) . \mathrm{f}(0,0)=0, \mathrm{f}(0,1)=1, \\
& \mathrm{f}(1,0)=1 \text { and } \mathrm{f}(1,1)=1 . \mathrm{B}_{1}(=\mathrm{f} 2) . \\
& \mathrm{f}(0,0)=0, \mathrm{f}(0,1)=0, \\
& \mathrm{f}(1,0)=0 \text { and } \mathrm{f}(1,1)=1 .
\end{aligned}
$$

Two separate networks were trained to perform the functions $B_{1}$ and $B_{2}$ using their respective input output pairs. The result was a one hidden layer network with one hidden unit. Each network was then augmented with an additional hidden unit and then and evaluated 1000 times using the scheme outlined in Section $2(\alpha=1, \beta=1.5$ with $T h$ is fixed at 0.5 ). Table 3 shows the results. From this result, we observe that this approach is also able to generate all binary monotone-increasing functions. However if we use either function $f 3$ or $\mathrm{f} 4$ as the teaching function, we fail. For example, if we train a network according to functions $\mathrm{f} 3$ and then apply the imagination step, we cannot generate function $\mathrm{f} 4$.

Considering Tables 2 and 3, the "Error pattern" on fuzzy teaching data are smaller than those

\begin{tabular}{|c|c|c|}
\hline function & $\begin{array}{c}\text { teaching } \\
\text { data B I }\end{array}$ & $\begin{array}{l}\text { teaching } \\
\text { data B2 }\end{array}$ \\
\hline f1 & 99 & 229 \\
\hline f2 & 13 & 507 \\
\hline $\mathrm{f3}$ & 60 & 36 \\
\hline f4 & 48 & 41 \\
\hline f5 & 458 & 44 \\
\hline $\mathrm{f6}$ & 261 & 120 \\
\hline sum\# & 937 & 977 \\
\hline $\begin{array}{c}\text { Error } \\
\text { pattern : \# }\end{array}$ & $\begin{array}{l}0100: 28 \\
0010: 33\end{array}$ & $\begin{array}{c}1001: 2 \\
1011: 12 \\
1101: 9\end{array}$ \\
\hline Error\# & 61 & 23 \\
\hline
\end{tabular}
of Table 3, where the number of input/output
Table 3 A result of two-variable functions with binary functions.

pairs is of same. Thus, teaching data based on fuzzy sets is more effective in expressing the concept of monotone-increasing functions than binary teaching data. We have similar results from experiments in generating monotone-decreasing functions.

Problem 2: Generate strong monotone-functions which satisfy $f(0,0) \leq f(0,1) \leq f(1,0) \leq f(1,1)$.

Fuzzy Training Data Solution: We can express the teaching data by the fuzzy set below:

$$
\begin{aligned}
F_{2}= & 0.0 /(0,0)+0.33 /(0,1)+0.67 /(1,0) \\
& +1.0 /(1,1)
\end{aligned}
$$

According to $F_{2}$, our teaching data are determined as four input/output pairs: $\mathrm{f}(0,0)=0.0, \mathrm{f}(0,1)=$ $0.33, f(1,0)=0.67$ and $f(1,1)=1.0$ on our network learning algorithm. We simulate it in the same way as in problem 1 . When we use a binary function to generate the teaching data, we must select either B 1 or B 2 or another function, B 3 , that satisfies $f(0,0)=0, f(0,1)=0, f(1,0)=1$ and $\mathrm{f}(1,1)=1$. Table 4 shows that we can generate all the functions by using any teaching data and that the use of fuzzy teaching data produces a better result than that of binary data according to the "Error pattern" result.

Table 2 A result of two-variable monotone-increasing functions.

\begin{tabular}{|c|c|c|c|c|c|c|c|c|c|}
\hline Th & 0.1 & 0.2 & 0.3 & 0.4 & 0.5 & 0.6 & 0.7 & 0.8 & 0.9 \\
\hline \hline f1 & 43 & 96 & 124 & 159 & 184 & 217 & 297 & 411 & 712 \\
\hline f2 & 48 & 47 & 81 & 106 & 239 & 401 & 363 & 313 & 86 \\
\hline f3 & 38 & 51 & 44 & 54 & 32 & 45 & 65 & 59 & 44 \\
\hline f4 & 35 & 64 & 67 & 61 & 38 & 47 & 56 & 59 & 39 \\
\hline f5 & 120 & 262 & 354 & 370 & 328 & 140 & 85 & 62 & 54 \\
\hline f6 & 695 & 466 & 316 & 242 & 179 & 144 & 123 & 84 & 37 \\
\hline \hline sum\# & 979 & 986 & 986 & 992 & 1000 & 994 & 989 & 988 & 972 \\
\hline \hline \multirow{3}{*}{ Error } & $1011: 6$ & $0100: 7$ & $0010: 9$ & $0100: 5$ & & $1101: 3$ & $1101: 7$ & $1101: 7$ & $0100:$ \\
pattern & $0101: 4$ & $0010: 7$ & $0100: 5$ & $0010: 3$ & & $1011: 3$ & $1011: 4$ & $1011: 5$ & 10 \\
$: \#$ & $0010: 3$ & & & & & & & & $0010: 6$ \\
& $1100: 1$ & & & & & & & & $1101: 5$ \\
& $1001: 1$ & & & & & & & & $1000: 3$ \\
& $1110: 1$ & & & & & & & & $1110: 1$ \\
& $1001: 1$ & & & & & & & & \\
\hline Error\# & 21 & 14 & 14 & 8 & 0 & 6 & 11 & 12 & 28 \\
\hline
\end{tabular}


Table 4 comparison of teaching data.

\begin{tabular}{|c|c|c|c|c|c|}
\hline \multirow{2}{*}{} & \multicolumn{2}{|c|}{ fuzzy data } & \multicolumn{3}{c|}{ binary data } \\
\cline { 4 - 6 } & & & (B1) & $(\mathbf{B} 2)$ & (B3) \\
\hline \hline Th & 0.33 & 0.5 & 0.5 & 0.5 & 0.5 \\
\hline f1 & 167 & 133 & 99 & 229 & 148 \\
\hline f2 & 139 & 126 & 13 & 507 & 35 \\
\hline 3 & 364 & 198 & 60 & 36 & 500 \\
\hline f5 & 144 & 332 & 458 & 44 & 64 \\
\hline f6 & 153 & 193 & 261 & 120 & 127 \\
\hline \hline sum\# & 967 & 982 & 891 & 936 & 874 \\
\hline \hline Error & $0010: 13$ & $0010: 18$ & $0100: 28$ & $1001: 2$ & $0010: 47$ \\
pattern: \# & $1010: 20$ & & $0010: 33$ & $1011: 12$ & $1011: 79$ \\
& & & $0101: 48$ & $1101: 9$ & \\
\hline Error\# & 33 & 18 & 109 & 64 & 126 \\
\hline
\end{tabular}

Problem 3: Generate three-variable monotone functions.

Fuzzy Training Data Solution: When we use the same method for determining the teaching data, we obtain the following fuzzy teaching data:

$$
\begin{aligned}
F_{3}= & 0 /(0,0,0)+0.33 /(0,0,1) \\
& +0.33 /(0,1,0)+0.33 /(1,0,0)+0.67 /
\end{aligned}
$$

$(0,1,1)$

$$
+0.67 /(1,0,1)+0.67 /(1,1,0)+1 /(1,1,1)
$$

After training, we obtained a network with one hidden layer with three hidden units. We then applied the imagination step 1000 times using $\alpha=$ $3, \beta=1.5$. The result is tabulated in Table 5 . This result show that we can successfully generate all monotone-increasing functions when using $T h=$ 0.3 and 0.33 , but not when $T h=0.5$ or 0.67 .

\section{Threshold Sensitivity}

In this section, we examine the relationship between the fuzzy teaching data, the network output statistics, and threshold value, $T h$. We show histogram results of the problem of generating monotone-increasing functions in Sect. 3. Figure 2 (a) shows a histogram of output ' 1 's for twovariable inputs when $T h=0.5$ on the fuzzy training data result. Figure 2(b) shows that for 3-variable '1's when $T h=0.3$ on the fuzzy training data result. Figure 2 shows a strong relation between teaching data and the histogram. That is, the percentage of each output value against the total number of possible output values is similar to each of the fuzzy outputs in Figure 2 (a).

Next, we investigate how the $T h$ value works. Figure 3 shows a histogram of learning input/output pairs of $f(A)=0.3(A=(0,0)), f(B)=0.5(B=$ $(0,1)), f(1,0)=0.9(C=(1,0))$ and $f(D)=0.4(D=$

\begin{tabular}{|c|c|c|c|c|c|c|c|c|c|}
\hline $\mathrm{x} 1$ & $\begin{array}{llll}0 & 0 & 0\end{array}$ & 0 & 11 & 1 & & \multicolumn{4}{|c|}{ histogram } \\
\hline$x 2$ & $\begin{array}{lll}0 & 0 & 1\end{array}$ & 1 & 00 & 1 & & Th. & Th. & Th. & Th. \\
\hline $\mathrm{x} 3$ & $\begin{array}{lll}0 & 1 & 0\end{array}$ & 1 & $\begin{array}{ll}0 & 1\end{array}$ & 0 & & 0.3 & 0.33 & 0.5 & 0.67 \\
\hline f1 & $\begin{array}{lll}0 & 0 & 0\end{array}$ & $\overline{0}$ & 50 & 0 & & 801 & 899 & 1411 & 2315 \\
\hline $\mathrm{f} 2$ & $\begin{array}{llll}0 & 0 & 0\end{array}$ & $\overline{0}$ & $\overline{00}$ & 0 & I & 200 & 217 & 285 & 183 \\
\hline f3 & $\begin{array}{lll}0 & 0 & 0\end{array}$ & $T$ & $\overline{00}$ & $\overline{0}$ & i & 107 & 116 & 147 & 146 \\
\hline $\mathrm{f} 4$ & $\begin{array}{lll}0 & 0 & 0\end{array}$ & $\overline{0}$ & 01 & $\overline{0}$ & & 96 & 107 & 157 & 283 \\
\hline f5 & 000 & $\overline{0}$ & 50 & 1 & & 124 & 121 & 170 & 252 \\
\hline f6 & 000 & 1 & 01 & 0 & & 76 & 146 & 192 & 90 \\
\hline f7 & $\begin{array}{lll}0 & 0 & 0\end{array}$ & 1 & 00 & 1 & & $\overline{93}$ & 147 & 157 & 86 \\
\hline f8 & 000 & 0 & 01 & 1 & 1 & 100 & 134 & 212 & 181 \\
\hline f9 & 000 & 1 & 01 & 1 & 1 & 1030 & 1819 & 3718 & 3068 \\
\hline f10 & 01 & 1 & 01 & 0 & 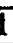 & 73 & 8 & 0 & 0 \\
\hline f11 & $\begin{array}{lll}0 & 0 & 1 \\
\end{array}$ & 1 & $\overline{00}$ & 1 & I & 61 & 4 & 0 & 0 \\
\hline f12 & 0000 & $\overline{0}$ & 11 & 1 & 1 & 81 & 38 & 0 & 0 \\
\hline f13 & $\begin{array}{lll}0 & 0 & 0\end{array}$ & $\overline{1}$ & 11 & 1 & 1 & 185 & 308 & 243 & 209 \\
\hline f14 & $\begin{array}{lll}0 & 0 & 1\end{array}$ & $T$ & $\overline{01}$ & 7 & I & 156 & 122 & 199 & 173 \\
\hline f15 & $\begin{array}{lll}0 & 1 & 0 \\
\end{array}$ & ( & 01 & 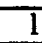 & I & 174 & 127 & 224 & 197 \\
\hline f16 & $\begin{array}{lll}0 & 1 & 1 \\
\end{array}$ & 1 & 01 & 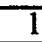 & I & 177 & 53 & 180 & 145 \\
\hline f17 & 010 & 1 & 11 & . & & 233 & 99 & 205 & 141 \\
\hline f18 & $\begin{array}{lll}0 & 0 & 1\end{array}$ & 1 & 11 & 1 & & 239 & 102 & 177 & 136 \\
\hline f19 & 01 & 1 & 11 & & & 2907 & 2572 & 335 & 244 \\
\hline $\mathrm{f} 20$ & 111 & I & 11 & 1 & & 2856 & 2629 & 1482 & 914 \\
\hline & sum & & & & & 9769 & 9768 & 9494 & 9763 \\
\hline
\end{tabular}

Table $5 \mathrm{~A}$ result of three-variable monotone-increasing functions.

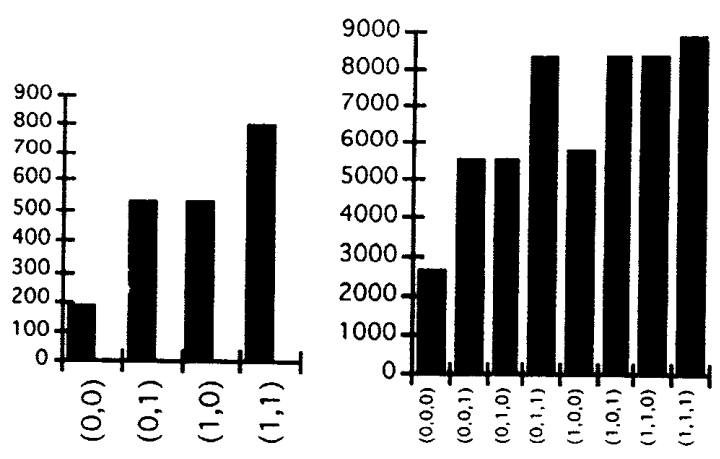

(a) two-variable case (b) three-variable casse

Figure 2 The histograms of outputs. 
$(1,1))$ when we changed the Th. value from 0.1 to 0.9. For each histogram A, B, C and D, a sudden change occurs at the value of fuzzy degree, that is, for $A$, it occurred between 0.3 and 0.4 . When we consider the percentage against 1000 , the values for $T h=0.5$ are closest to the output values. Therefore, we will use $T h=0.5$ in the following sections.

\section{A Decision Making Model}

In this section, we apply our model to decision making, a typical human task.

Problem : Consider the situation of selecting clothes in a shop with four types of clothes. The estimated degree of favoritism and good-price of each article of clothing for a person who is considering to buy them shown in Table 6 (a higher value indicates a higher evaluation of them). We treat favoritism and good-price degrees with equity.

For this problem, clothes A, B, C and D are encoded to two-variable binary input vectors $(0,0),(0,1),(1,0)$ and $(1,1)$, respectively. We obtained a one hidden layer network with six hidden units. We then performed the imagination step 1000 times using $\alpha=3$ and $\beta=1.5$. The result is tabulated in Table 7 . We will select the clothes according to a degree of "summing the histograms (adding the histogram values), " because we assume both factors are treated with equity. Our model then solves the problem in the following way:

if we want to buy only one piece of clothing

$\Rightarrow$ we should buy $\mathrm{C}$.

if we want to buy two pieces of clothing

$\Rightarrow$ we should buy $A$ and $B$,

if we want to buy three pieces of clothing

$\Rightarrow$ we should buy A, B and D.

The sum of both values in Table 6 is $A=1.0, B=$ $1.1, C=1.2$ and $D=0.9$. According to these values, we should select C, B, A and D. Our model chooses $\mathrm{C}$ when one is needed. In the case of seeding two articles, it avoids to select $C$, because $C$ is most expensive. In the case of seeding three articles, the total price of A, B and D are good.

\section{Generation of Images}

Pattern recognition techniques are widely used to develop automated machine control and for recognizing objects such as cars, planes, tanks and so on. In particular, moving object recognition is difficult because an image may be incomplete, include noise, and/or include unnecessary parts. To

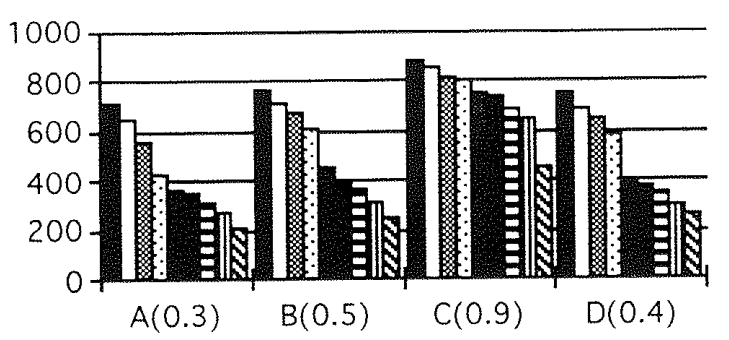

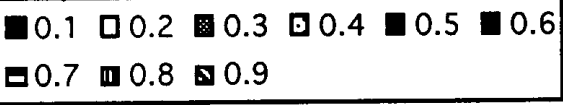

Figure 3 A histogram variation when changing Th.

Table 6 A estimation value for cloths.

\begin{tabular}{|c|c|c|c|c|}
\hline Cloth & A & B & C & D \\
\hline favoritism P & 0.3 & 0.5 & 0.9 & 0.4 \\
\hline good-price Q & 0.7 & 0.6 & 0.3 & 0.5 \\
\hline
\end{tabular}

Table 7 A simulation result for Table 6 .

\begin{tabular}{|c||c|c|c|}
\hline clothes & $\begin{array}{c}\text { histogram } \\
\text { for favor- } \\
\text { itism P }\end{array}$ & $\begin{array}{c}\text { histogram } \\
\text { for good- } \\
\text { price Q }\end{array}$ & $\begin{array}{c}\text { sum of } \\
\text { P and Q }\end{array}$ \\
\hline \hline Nothing & 235 & 289 & 528 \\
\hline A & 6 & 77 & 83 \\
\hline B & 31 & 31 & 62 \\
\hline C & 183 & 13 & 197 \\
\hline$D$ & 4 & 15 & 19 \\
\hline$A+B$ & 9 & 52 & 61 \\
\hline$A+C$ & 24 & 12 & 36 \\
\hline$A+D$ & 0 & 8 & 8 \\
\hline$B+C$ & 27 & 0 & 27 \\
\hline$B+D$ & 13 & 21 & 34 \\
\hline$C+D$ & 32 & 12 & 44 \\
\hline$A+B+C$ & 38 & 7 & 45 \\
\hline$A+B+D$ & 1 & 98 & 99 \\
\hline$A+C+D$ & 19 & 25 & 44 \\
\hline$B+C+D$ & 77 & 8 & 85 \\
\hline all & 300 & 332 & 632 \\
\hline
\end{tabular}

perform the recognition, we must first consider the variations of the objects to be recognized. That is, for cars, we must consider if it is a convertible, sedan, bus, minivan and so on. Developing automated pattern generation techniques might be useful for this applications.

As an example, we construct $5 \times 3$ pixel car images (see Figure 4). We use a two hidden layered model with three units in the first hidden layer and two in the second hidden layer. (The network has four inputs and one output). Figure 5 shows imaginary images generated from the network model of the car image. Table 8 shows the ratio of the images recognized as a car to 100 generated images. Considering Table 8 , the unit number in imagination unit can change the variety of generated patterns more efficiently, compared to the case of changing coefficients a and b. Moreover, 
we can see that a variety of generated images can be tractable by setting adequate coefficients $a, b$ and added unit number in imagination units.

Next, we generated $16 \times 8$ pixel car images from a core teaching image shown in Figure 6 . We constructed a seven input one output network with four hidden layer containing seven, two, one and three hidden units, respectively. Figure 7 shows the core image and some of the imagined images. One more experimental result for the another core image is also shown in Figure 8.

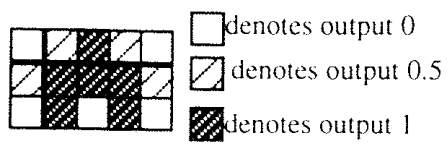

Figure 4 A teaching image $(5 \times 3)$.
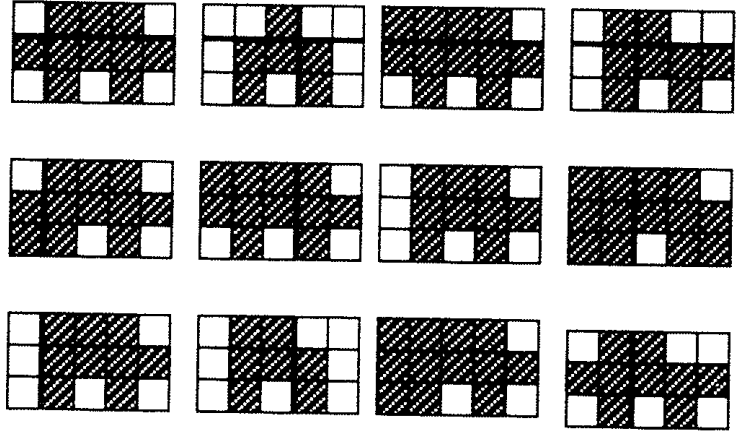

Figure 5 A result for Figure 4.

Table 8 Relationship between added unit number, coefficients $a$ and $b$ and the ratio.

\begin{tabular}{|c|c|c|}
\hline $\begin{array}{c}\text { coefficients } \\
\alpha \text { and } \beta\end{array}$ & added unit \# & ratio (\%) \\
\hline \hline 1 & 2 & 46 \\
\hline 2 & 2 & 45 \\
\hline 3 & 2 & 45 \\
\hline 4 & 2 & 25 \\
\hline \hline 2 & 1 & 66 \\
\hline 2 & 2 & 46 \\
\hline 2 & 3 & 25 \\
\hline 2 & 4 & 12 \\
\hline
\end{tabular}

\begin{tabular}{|l|}
0000000000000000 \\
$* * * * * * * * * * * * 00$ \\
$* * * * * 111111 * * * 00$ \\
$* * * * * 111111 * * * 00$ \\
1111111111111110 \\
1111111111111111 \\
1111111111111111 \\
0001110000011100
\end{tabular}

Figure 6 A teaching image $(16 \times 8)$

(* denotes output 0.5 ).

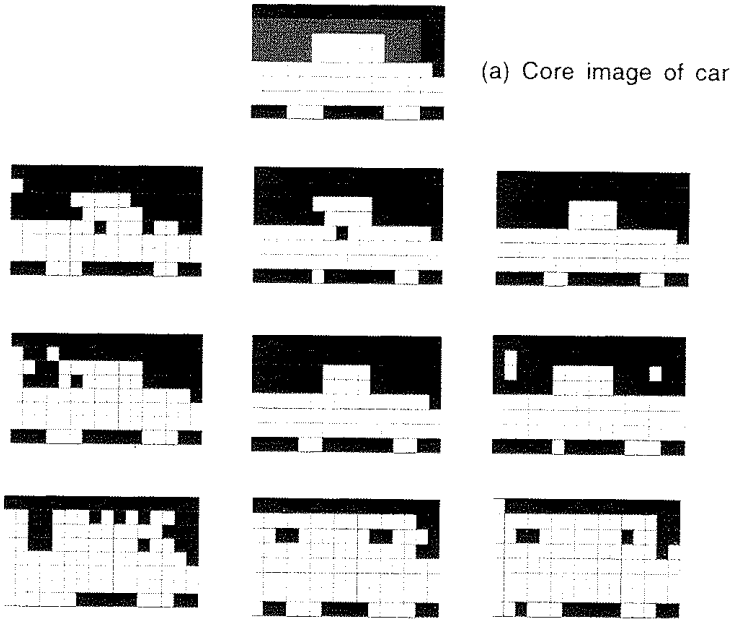

(b) Some generated images

Figure 7 The core image and some henerated images.

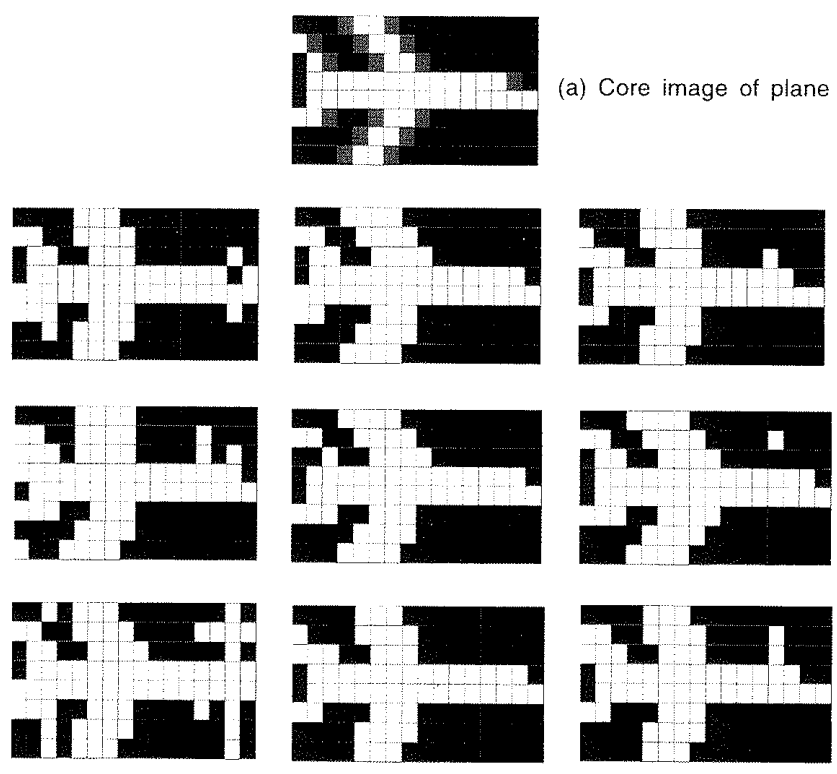

(b) Some generated images

Figure 8 An example for generating plane images.

\section{Conclusions}

This paper investigates a novel technique for constructing a neural model of pattern generation. Our technique involves a data modeling step followed by an Imagination Step. The imagination step augments the trained network, which is then used to create, or synthesize, variations on the trained data. Experiments performed on simple examples demonstrate a potential of our model. 
Acknowledgment

Research supported in part by NASA Grant NCC 2 -275, ONR Grant N 00014-96-1-0556, LLNL Grant 442427-26449, ARO Grant DAAH 04-9610341, and the BISC Program of UC Berkeley.

\section{REFERENCE}

[ 1 ] Rumelhart D.E., McClelland J.L. and PDP Research Group, Parallel Distributive Processing, Vols.1 and 2, MIT Press (1986).

[2 ]Rumelhart D.E., Hinton, G.E. and Williams, R.J., "Learning representations by back-propagating errors", Nature, 323, pp.533-536, (1986).

[ 3 ]Zadeh L.A., Fuzzy Sets and Applications (selected papers), John Wiley and Sons, Inc. (1987).

[ 4 ] Paval M., Gluck M.A. and Henkle V. "Constraints on adaptive networks for modeling human generalization" Advance in neural information processing systems 1., Morgan Kaufmann Pub. pp.2-10 (1989).

[ 5 ] Massaro D.W. "The Psychology of Connectionism", Behavior and Brain Science, pp.403-406 (1990)

[6] Massaro D.W. Connectionist Models of Speech Perception, in Connectionist Approaches to Natural Language Processing, Lawrence Eribaum Asso. ciates Pub. pp.321-350 (1992)

[ 7 ] Massaro D.W., "Some Criticisms of Connectionist Models of Human Performance", Journal of Memory and Language, 27, pp.213-234(1988)
[ 8 ] Massaro D.W., "A Pattern Recognition Account of Decision Making”, Memory and Cognition, 22, 5, pp.616-627 (1994)

[ 9 ] Massaro D.W., "The Paradigm and the Fuzzy Logical Model of Perception are Alive and Well", Journal of Experimental Psychology, 122, 1, pp.115124 (1993)

[10] Hata Y., Hozumi T. and Yamato K. "Gate model networks for minimization of multiple-valued logic functions" IEEE Proc. 23rd-Int.Symp. on MultipleValued Logic, pp.29-34 (1993).

[11] Hata Y., Hozumi T.and Yamato K. "System Design Based on Neural Computing", IEEE Proc. of the 3 rd-Int. Conf. on Systems Integration, pp.197205 (1994).

[12] Hata Y. , Lee M.A. and Yamato K., "A Neuro-Fuzzy Computing Model for Human Pattern Generation", IEEE Proc. of North American Fuzzy Information Processing Society, pp.336-341(1996)

（1996年11月19日 受 付） (1997年 8月26日 再受付)

[問い合わせ先］

T671-22 姫路市書写2167

姫路工業大学情報工学科

畑 豊

TEL : 0792-66-1661

FAX : 0792-66-8868

E-mail : hata@ comp.eng.himeji-tech.ac.jp
著 者 紹 介

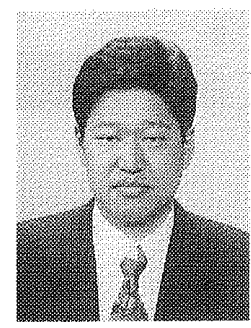

\section{Yutaka HATA}

Department of Computer Engineering, Himeji Institute of Technology

Yutaka Hata was born in Hyogo on May 30, 1961. He received the $\mathrm{BE}$ degree (Electronics) in 1984, the ME degree in 1986 and the DE degree in 1989 from Himeji Institute of Technology. He is currently an associate professor in the Department of Computer Engineering, Himeji Institute of Technology. He spent one year in University of California at Berkeley from 1995. He is now a visiting professor in Computer Science Division, University of California at Berkeley. His research interests include soft computing, medical imaging and multiple-valued logic. He is a member of the IEEE, the Institute of Electronics, Information and Communication Engineers, Japan Society for Fuzzy Theory and Systems and Japan Society of Medical Electronics and Biological Engineering.

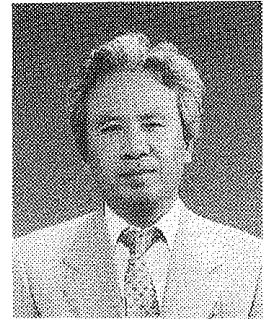

\section{Makoto ISHIKAWA}

Ishikawa Hospital

Makoto Ishikawa was born in Hyogo on April 9, 1940. He graduated School of Medicine, Kobe University in 1965 . He is currently the president in Ishikawa Hospital. He spent one year in West Chester County Hospital, USA. His research interests include radiology surgery and soft computing. He is a member of Japan Surgical Society, Japanese Gastroenterorogical Surgery, .Gastroenterorogical Endoscopy, Japanese Hyperthermic Oncology and Japanese Oriental Medicine. 


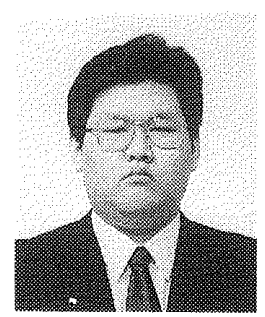

\section{Naotake KAMIURA}

Department of Computer Engineering, Himeji Institute of Technology

Naotake Kamiura was born in Hyogo on February 3, 1967. He received the $\mathrm{BE}$ (Electronic Engineering) degree in 1990 , the $\mathrm{ME}$ degree in 1992 and the DE degree in 1995 from Himeji Institute of Technology. $\mathrm{He}$ is currently a research associate in the Department of Computer Engineering, Himeji Institute of Technology. His current research interests include multiple-valued logic and fault tolerance. He is a member of the Institute of Electronics, Information and Communication Engineersand the IEEE.

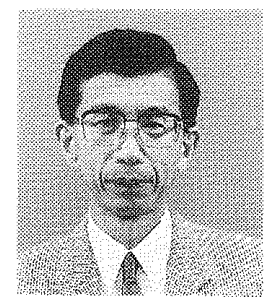

\section{Riichi NAGURA}

Department of Computer Engineering, Himeji Institute of Technology

Riichi Nagura was born in Tokyo on Dec 11, 1938. He received the BE degree in 1961 and the DE degree in 1994 from Yokohama National University. He is currently a professor in the Department of Computer Engineering, Himeji Institute of Technology. He had developed Japanese high resolution earth observation equipments on board many kinds of satellites including stereo imaging systems and high speed data transmission systems. Now, his research interests include stereo image information analysis and adaptive image compression systems. $\mathrm{He}$ is a member of the Institute of Electronics, Information and Communication Engineers, Electrical Society and Adviser, Japan Remote Sensing Society.

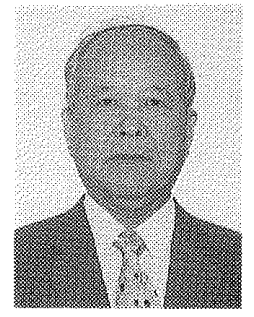

\section{Kazuharu YAMATO}

Department of Information and Systems Engineering, Fukuoka Institute of Technology

Kazuharu Yamato was born in Hyogo on May 23, 1931. He received the $B E$ degree (Electrical Engineering) in 1954 from Himeji Institute of Technology and the DE degree in 1968 from Osaka University. He is currently a professor in Department of Information and Systems Engineering, Fukuoka Institute of Technology. His research interests include system reliability and safety, information security, multiple-valued logic and image processing. $\mathrm{He}$ is a member of the Institute of Electronics, Information and Communication Engineers and the Institute of Image Elec. tronics Engineers of Japan.

\title{
A Pattern Generation Model Based on Neural Network
}

\author{
by
}

\section{Yutaka HATA, Makoto ISHIKAWA, Naotake KAMIURA, Riichi NAGURA and Kazuharu YAMATO}

\section{Abstract :}

This paper investigates a novel technique for constructing and evaluating neuro-models of pattern generation. The modeling approach consists of two steps : first a neural network is trained to learn a core concept expressed on fuzzy logic, and then the trained network is augmented with additional processing nodes and connections. The augmented network is then tested on its ability to solve problems related to the core concept for which it was trained. We present results from applying our model to monotone-function generation, decision making and image generation.

Keywords : Neural Networks, Pattern Generation, Back Propagation, Soft Computing

\section{Contact Address : Yutaka HATA}

Department of Computer Engineering, Himeji Institute of Technology

2167, Shosha, Himeji, 671-22, Japan

TEL : :0792-67-4986

FAX : 0792-66-8868

E-mail : hata@ comp.eng.himeji-tech.ac.jp 


\section{ニューラルネットワークを用いたパターン発生モデル}

本文では，ニューラルネットワークを䏘たパターン発怆のモデルについて報出する。このモデルの川的

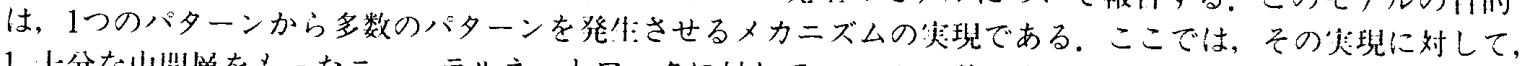

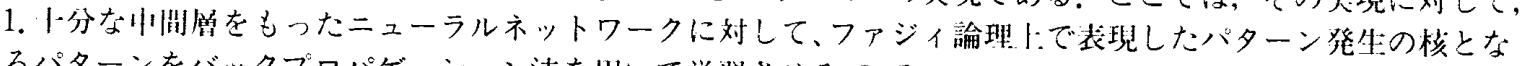

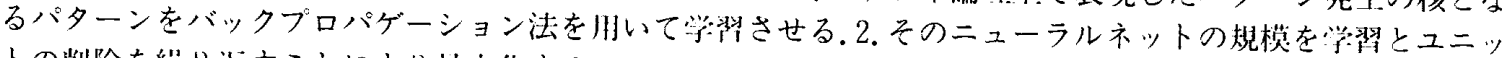

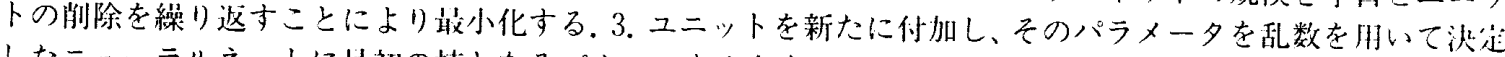

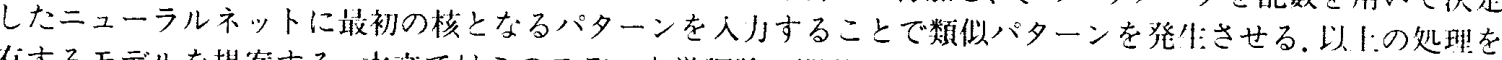

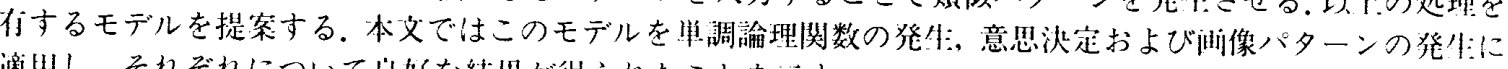
適用し，それぞれについて度好な結果が得られたことを示す。

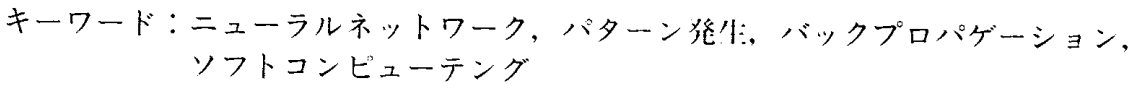

